\title{
A REVIEW STUDY ON IMPACT OF DIETARY SUPPLEMENT FRAUDS ON PUBLIC HEALTH
}

\author{
Dr. Manjiri Jengathe \\ MBA (HHM- Hospital and Healthcare Management), \\ Symbiosis International University, Pune, India
}

\begin{abstract}
Keeping in view of the possibility of false and misleading claims of food supplements that the corporate sector likely to make for monetary gains the U.S. Food and Drugs Administration, Federal Trade Commission, Europian Union Food Safety Authority, FSSA India and many other globally recognized food safety management agencies are held responsible to keep watch on such misleading food claims. In fact, millions of global population consume dietary supplements hoping to maintain better health. However, number of researches have been failed to demonstrate the efficacy of the supplements. If composition, quality and claims are found unreliable, the validity of research will remain questionable. It may be due to monitoring authorities and their regulatory loopholes that allow the producers and suppliers to use them for monetary gains, for which they claim the nutrient contents unreliably for health benefits. On the way they ignore side effects, health risk and warning of the researchers. Such malpractices made the global food market flooded with unhealthy supplements as a magical brand of super food in the name of emotional branding. Thus, on one hand dietary supplement frauds have been upheld from global agencies and industries and on the other hand there is a growing awareness about the public health threat. There are increasing consequences with the increasing consumption of such products. These products are classified as economically motivated adulteration. Dietary supplements fraud may cause greater public health threat than traditional dietary supplements safety issues. The purpose of this article is to provide comprehensive overview on the public health threat of dietary supplement frauds (DSF).
\end{abstract}

Key words: Dietary Supplement Frauds; Global market; Emotional branding; Economic gains; Fraudsters; Public health; Superfood market; Food adulteration.

Cite this Article: Manjiri Jengathe, A Review Study on Impact of Dietary Supplement Frauds on Public Health, International Journal of Management, 11(12), 2020, pp. 2660-2668.

http://iaeme.com/Home/issue/IJM?Volume=11\&Issue $=12$ 


\section{OBJECTIVES}

The main objectives of this study are to review global food system and its various components and to study the concept of diet in the scope of world health organization. According to WHO, sustainable and healthy diet is a dietary pattern that promotes all dimensions of health and wellbeing such as having low environmental impact, accessible, affordable, safe, equitable and socio-culturally acceptable. Aims are to achieve optional growth and development of all individuals from present and future generation. It is to contribute to presenting all forms of malnutrition i.e. under nutrition, micronutrient deficiency, overweight and obesity. This study will help to reduce risk of diet related diseases and support preservation of biodiversity and planetary health. Diet must combine all dimensions of sustainability to avoid adverse consequences. Global population needs to be aware of the hyper marketing of speciality supplements creating high risk to the sustainable and healthy diet containing whole grains, fruits and vegetables including moderate amount of eggs, dairy, poultry, fish and meat with safe and clean drinking water. The study will concentrate on whether the requirement of energy and nutrients are consistence with WHO guidelines. Whether the supplements are free from pathogens and toxins to avoid foodborne diseases. The study will also tend to measure the impact on biodiversity along with socio-cultural and local adaptability. The focus of this study is to provide insight into the aspect of growing global food fraud affecting the traditional dietary system and alert the people from the new challenges to public health.

\section{INTRODUCTION}

Dietary supplement fraud is the fraud conducted for economic gains using dietary supplements. The Europian Union considers dietary supplements as food supplements while the U.S. food and Drug Administration defines them as a specific product separated from food since they have drug's effects within human body. The concept of food fraud has been characterized as the intentional substitution, addition, tampering, misrepresentation of food, food ingredients or food packaging or misleading statements made about the product for economic gains. But since such act can lead to adverse public health consequences, it may be considered more risky and harmful than traditional food safety threats. Today we are made to believe the unbelievable that so called spiritual Guru Osho and Satya Sai were selling spirituality under the package of Yoga therapy to treat our body and mind. Similarly, India's Spiritual Guru, Baba Ramdeo or Vikram Chaudhari selling supplements and health products under the package of Yoga is no more than the multimillionaire corporates are selling scientifically unproven food supplements for the economic gains. The dietary supplement frauds made by emotional branding is the major public health threat. Unless the regulatory bodies, scientists and health authorities step forward to revoke such frauds the public health can never be justified.

In 2007 the Europian Union put ban on super food branding without any authentic scientific evidence of the claims noted on the label. Harvard Health Publishing has given warnings against selling such brands to protect public health. Emotional branding dig out the years long impression of the word super that make the people easily motivated by the words like superpower, super food or super diet. Due to constant propaganda even fraud supplements have become extremely popular without any scientific evidence of their health benefits. It has now potential enough to change our idea of healthy diet and nutrition. Corporate controlled internet and social media are constantly manipulating human minds and pushing them in favour of the fake dietary supplements. As soon as we enter the virtual world of internet and social media, we stuck into it. Being confused with the content variation people are at high risk to be deceived with such false health claims. So, people should be aware of certain myths of such dietary supplements. 


\section{BACKGROUND}

A notable incident of adverse public health caused by dietary supplements first occurred in 1989 when an outbreak of Eosinophilia Myalgia Syndrome emerged. The Center for Disease Control and Prevention (CDC) estimated that over 1500 people who had consumed the supplements, experienced fatigue, breathe shortness and other health problems. The CDC confirmed 38 deaths due to L-tryptophan consumption. Evidence revealed that the products made with contaminated batches entered the market and harmed the public health. As a result of this outbreak, the U.S. food and Drug Administration (FDA) put ban on the counter sale of L-tryptophan in 1990. In 2004 FDA also put a ban on dietary supplements with alkaloid ingredients. For ex the weight loss products marketed as Ephedra containing ephedrine increases the risk of illness or injury, like heart attack or strokes. In 2007 it was revealed that the firm had deliberately concealed over 1000 adverse health complaints and continued its market. These incidents are the direct result of fraudulent dietary supplements.

Walmart is the major retailer of dietary supplements through internet, under the category of multivitamins, vitamins A to Z, dietary supplements herbals, fish oils, weight loss supplements, glucose, bone and joint supplements and minerals. But they are misleading, as the average consumers can't identity the line between drug and dietary supplements. According to CODEX guidelines of 2005 and 2007, all supplements should follow the standards set by WHO, the supplement package should contain a list of ingredients and warning not to replace regular food.

EU regulations focus on food safety and labelling of the supplements. Europian Commission's Food Safety Authority, Federal Food Drug and Cosmetic Act are working in the approval process. US Food and Drug Administration and FSSAS. India are also playing their role in the same. A study published in the journal of the American Medical Association Stated that $21 \%$ sample of Ayurvedic medicine contained detectable level of heavy metals. Several such products in India found heavy metals 100 to 1000 times more than prescribed limit. According to FDA misbranded dietary supplements are being sold globally. The FDA and Federal Trade Commission have already put ban on selling such products.

Dietary supplements used in U.S. have been increased since National Health and Nutrition Exam Survey. In 1994 Dietary Supplement Health and Education Act made separate category of food under separate regulation. In 2011 Food Safety Modernization Act was established to protect food safety.

\section{OBSERVATION}

It is interesting to know, how emotional branding with false health claims represents the traditional diets as super foods and selling them at higher rate. In Harvard Health Service Public Access of Nutr Cancer. Dr. Oz Shows Anti-Cancer-Diet like Endive, Red Onion, Sea bass that can decrease a risk of ovarian cancer by $70 \%$. It claims that kaempterol, a flavonoid found in Endive, induces apoptosis in ovarian cancer cells and block angiogenesis. But connection of Endive intake with ovarian cancer may have by chance, because no connection of ovarian cancer was found for other vegetables that provide more flavonoid. (See Table) 
Table 1 Dietary source of flavonoid

\begin{tabular}{|l|l|}
\hline \multicolumn{1}{|c|}{ Food Item } & \multicolumn{1}{c|}{ Flavonoid (mg/100g) } \\
\hline Kale & 46.80 \\
\hline Mustard Green (raw) & 38.30 \\
\hline Welsh Onion (raw) & 24.95 \\
\hline Water Cress (raw) & 23.03 \\
\hline Cabbage (raw) & 22.51 \\
\hline Cress (raw) & 13.00 \\
\hline Turnip Green (raw) & 11.87 \\
\hline Endive (raw) & 10.10 \\
\hline Chives (raw) & 10.00 \\
\hline Collards (raw) & 9.48 \\
\hline Radish Leaves (raw) & 7.72 \\
\hline Fennel Leaves (raw) & 6.50 \\
\hline Spinach (raw) & 6.38 \\
\hline Green Onion & 3.60 \\
\hline
\end{tabular}

(Source - U.S. Dept. of Agriculture - 2011)

Similarly, flavonoid in Red Onion is reported to prevent ovarian cancer. But Women's Health Study data reported no connection between onion intake and ovarian cancer risk.

Table 2

\begin{tabular}{|l|c|}
\hline \multicolumn{1}{|c|}{ Food Item } & Flavonoid (mg/100g) \\
\hline Welsh Onion & 24.95 \\
\hline Green Onion & 3.60 \\
\hline Red Onion & 35.00 \\
\hline White Onion & 69.20 \\
\hline Yellow Onion & 55.20 \\
\hline
\end{tabular}

According to this data the amount of flavonoid in Red Onion is found $35 \mathrm{mg}$, white onion $69.2 \mathrm{mg}$ and yellow onion $55.2 \mathrm{mg}$ per $100 \mathrm{~g}$. Here instead of white and yellow, only Red onion was recommended as anticancer. But whether Red onion contains flavonoid more than white or yellow is questionable.

Dr. Oz also shows that other foods as sea bass, due to high content Omega - 3 fatty acid, were claimed as anti-angiogenic. But the evidence of connection between fish intake and ovarian cancer risk is not justified. (See table 3)

Table 3

\begin{tabular}{|l|c|}
\hline \multicolumn{1}{|c|}{ Fish Species } & Omega $-\mathbf{3}$ (mg/100g) \\
\hline Mackerel & 2.51 \\
\hline Salmon & 2.36 \\
\hline Anchovy & 2.10 \\
\hline Herring & 1.83 \\
\hline Salmon Atlantic & 1.72 \\
\hline Herring Atlantic & 1.63 \\
\hline Mackerel Pacific & 1.56 \\
\hline Spanish Mackerel & 1.44 \\
\hline Tuna Bluefin & 1.30 \\
\hline Sardine & 0.98 \\
\hline Shark & 0.95 \\
\hline Trout & 0.91 \\
\hline Tuna Albacore & 0.88 \\
\hline Swordfish & 0.79 \\
\hline Bass & 0.75 \\
\hline Sea Bass & 0.67 \\
\hline
\end{tabular}

(Source - U.S. food and Drug Adm. 2010) 
The data shows that several other species have much higher content of omega -3 fatty acid as compared to sea bass. So, whether sea bass with negligible omega -3 can reduce ovarian cancer risk is still questionable. Dr. Leo Benedictus quoted in "The Guardian", a research was reported that omega -3 and antioxidants mop up free radicals causing ageing and cancer. But Europian Food Safety Authority pointed out that free radicals actually kill bacteria. Does it mean antioxidants weaken immune system? The truth is that, if you eat a balanced diet and do regular exercise, we need no supplements and if you don't, no supplements will save you.

Actually, the claims of health benefits of the dietary supplements are the marketing tools used for economic gains. Nuts claim protein and fat for smoothing brain function, but it may be a problem when eaten in excess. Similarly, excessive intake of Green tea may cause stomach and head aches. Sweet potatoes have high fibers, vitamins and minerals but excessive intake can increase blood sugar. Broccoli is claimed to be anti-inflammatory and lower cholesterol and regulate estrogen, but excessive intake may disrupt hormonal balance. Too much fiber rich cherries may cause diarrhea. Watermelon is claimed to have high vitamin - c like Broccoli, Cabbage is used to reduce cancer risk, but excessive intake may increase cholesterol level. Egg is a universal energy stabilizer but too much intake may raise cholesterol level. Turmeric is used universally as an anti-inflammatory, improving brain function and lowering cancer risk but excessive dose may cause diarrhea. Garlic and Ginger are immunity booster, but raw form may have adverse effect. Carrot is used for eye health, B.P. and anti cancer but excess dose may have harmful effect on skin.

Style Craze Medical Review of 17 September 2019 noted that microalgae chlorella and Spirullina for their nutritional value, are widely consumed. Spirulina, blue-green algae is a wonderful cyanobacteria contains 50 to $70 \%$ protein, $14 \%$ lipid, 1.5\% Carbohydrates, Vit. A, $\mathrm{B}, \mathrm{D}$, minerals and pigments like phycocyanin, carotenoid and chlorophyll. It is being sold on large scale in the global market. Despite its popularity its side effects are being neglected. Excess use may cause genetic disorder, damage immune system, risk of heavy metal toxicity harmful to liver, kidney and thyroid function and cardiovascular system. It may also affect neural function and increase a risk of Alzheimer, Parkinson, dementia or anxiety. Spirullina intake without expert's advice is very risky to children and pregnant women.

In October 2001, Steven Novella pointed out certain claims made by Cell Tech and other global marketers that Spirullina contains 50 to $70 \%$ proteins and amino acids that improves memory, vitality, sleep, weight loss, immunity and prevent cancer. A study published in December 2000 in the journal of medicinal foods by Dr. Eric Gerschain, pointed out that Spirullina boosts immune system. But Steven Novella remarked that these claims are not supported by any clinical research. So, the claims lacking of evidences have been a severe problem for the dietary supplements. In fact, without an approval of regulatory bodies how such claims can be made in a global market? Several researches reported very few diseases caused by nutritional deficiencies. If it is merely for the economic gains, then there is a great risk for the consumers to believe such claims of dietary supplements. Actually, specific health markers are required to support these health claims. Otherwise dietary supplements will remain as a brand slogan of food industry. Aren't they making a great mistake of neglecting auto immune diseases in which the immune system attacks its own body, generally occurred in Rheumatoid Arthritis, Multiple Sclerosis and Lupus?

News update on March 9, 2020, in The Washington Post says FDA \& FIC sent warning letter to seven companies, accusing them of marketing illegal, unproved drugs with their false claims to treat or cure COVID-19. Supreme Court in India also revoked marketing of drugs with false claims of treating COVID-19 by the firm of Baba Ramdev. 


\section{REPORT ON ECONOMICALLY MOTIVATED ADULTERATION}

Economically motivated adulteration i.e. dietary supplements fraud is observed in the following is most problematic ingredients during 1980 to 2010.

Table 4

\begin{tabular}{|c|l|c|}
\hline Sr. No. & \multicolumn{1}{|c|}{ Ingredients } & \% of adulteration \\
\hline 1. & Olive Oil & 14 \\
\hline 2. & Milk & 11 \\
\hline 3. & Honey & 7 \\
\hline 4. & Saffron & 5 \\
\hline 5. & Orange Juice & 4 \\
\hline 6. & Coffee & 3 \\
\hline 7. & Apple Juice & 2 \\
\hline 8. & Maple Syrup & 2 \\
\hline 9. & Vanilla & 2 \\
\hline 10. & Grape Wine & 1 \\
\hline 11. & Strawberry & 1 \\
\hline 12. & Beeswax & 1 \\
\hline 13. & Verum Hook & 1 \\
\hline 14. & Chinese Star Anise & 1 \\
\hline 15. & Milk Products & 1 \\
\hline 16. & Sesame Oil & \\
\hline
\end{tabular}

(Source - data published on core.ac.uk by Jeffry L. Moure jm@usp.org.)

The data shows that the above ingredients having severe adulteration, proved to be the most dangerous risk to public health. Despite the warning of the researchers and food monitoring authorities these supplements are being sold freely in the global market. This situation may prove to be more dangerous to public health.

\section{IMPACT}

Dietary supplement fraud has been proved to be great risk to sustainable health. Food contamination is reported to cause more than 200 foodborne diseases and 110 billion USD is lost every year in productivity and medical expenses in developing countries due to unsafe food. Contaminated food causes 550 million people fall ill, every year. Dietary food fraud affects socio-economic development. Food fraud often results in the reduction of quality rather than safety of the diet and consequently results in health complications. In 2008 Chinese milk formula was contaminated with melamine that affected around 3 lakh people. In 1981 a food fraud incident in Spain claimed thousands of deaths due to toxic oil syndrome. It was the most devastating food poisoning in modern European history that resulted in 1000 deaths and 25000 injured. About $74 \%$ mislabeled seafood was sold in restaurants and $18 \%$ in grocery, during 2014-15 thousands of tons of adulterated food were seized in Italy and Egypt. According to the Daily Mail, on February 25, 2013, horse meat isn't the only meat being substituted but Lamb Kabobs of lower quality is sold in British restaurants. Yahoo News reported that $90 \%$ of south African Kudu was actually horse, pork, beet, giraffe, kangaroo and even mountain zebra. According to Harvard Health Publishing report published in 2015 in the New England Journal of Medicine, adverse effects of supplements were responsible for 23000 visits of emergency dept. per year. According to a recent report of American Cancer Society, exposure to supplements accounted for more than one lakh health complaints were reported to U.S. poison control center in 2013. In all one should remember that if we take healthy diet and do exercise, we need no supplements but if we don't know supplement save us. 


\section{REGULATORY MEASURES}

\subsection{Results}

- In 1982 U.S. District Court ordered K. C. Laboratories to stop selling blue-green algae products for violating FDA regulations. The alleged Microalgae International Sales Corporation paid 225000 USD to settle charges of false claims of Spirullina. In a suit filed by Public Health Advocacy Institute, the deponent failed to produce evidence of health claims of the dietary supplements. (Source - www.celltech.com)

- According to journal Iww.com April 2019, U.S. FDA gave warning to companies selling more than 58 supplements claiming health benefit to mental disorder.

- According to Food Navigator - asia.com 28 November 2018, FSSA India rolled out Food Products Advertising Regulations that bans on using terms like natural, fresh, traditional, premium, authentic, genuine etc. on the label.

- In India U.P. High court imposed fine of Rs. 10 lakhs on Amway India Pvt. Ltd. For making false claims of dietary supplements.

- In India FSSA has begun prosecution against the accused companies, under Packaging and Labelling Regulations - 2011, on the false claims made there under. For ex. Complan, Boost, Horlicks, Emami, Saffola, Engine mustard oil, Nutricharge, Kellogs, Britannia, Bournvita, Premium tea, Nutrilite, Kisan Cream, Rajdhani Besan etc.

- Report of U.S. Dept. of Health and Services released on October 2, 2012 says claims of 127 dietary supplements for weight loss and immune system proved to be false due to lack to evidence. (Source - Poz.com October 2012)

- Living to smile.com, reported 10 adulterated China food are on radar, such as plastic rice, Garlic, Salt, Tilapia, Apple juice, Cod, Soybean, Mushroom and Corn.

- Recent study by ASSOCHAM and RNCUS reveals that $60-70 \%$ of fitness supplements are proved to be fake. Among them 40\% Vitamins, 30\% herbals, $10 \%$ probiotic, 5\% Omega -3 fatty acids, $15 \%$ Proteins are being marketed in the form of tablets, capsules, gels, liquids and powder. Dietary supplements have market of nearly 2 to 4 billion USD based on such fake products. (Source - Indiatimes.com December 8, 2015)

- Center for Science in Public Interest (CSPI) asked FDA and FTC to take action against 46 dietary supplements from Amazon due to their false claims of fighting against Covid-19 Virus. On May 5, 2020 it also asked Amazon to remove those products for public safety. (Source - foodpoisoningbulletin.com)

- February 12, 2020 article with headline, 'Vitamin C protects against Corona Virus' that was shared by more than 36000 users. Having no scientific evidence, they were declared fake and misleading by CDC and Harvard Health Publishing Authorities. (Source Factcheck.org)

\section{SUGGESTIONS}

Attitude towards safety, efficacy and values of food supplements in human society need to be changed in determining future need of food supplements. Much remains to be learned about the effects of bioactive constituents on public health. For this, the better and valid biomarker need to be developed. The association between supplement ingredients and health outcomes in chronic degenerative diseases must be clarified. Assessment of the safety, quality and efficacy of nutrients are needed to provide the reliable scientific information to the regulators.

Nutrition misinformation and dietary supplement fraud are not supported by science and may be misleading and affecting public health and socio-economic condition. Hence people should be aware of such fraudulent dietary supplements before consuming. Recommendations 
and promises of health benefits of the supplements need to be checked from the experts. Claims that sound too good to be true may be misleading and the part of their fraud conspiracy. People should not try to make conclusion merely from the claims of the marketers. Dramatic statements and research findings of some reputed scientific organizations may be a part of fraud conspiracy. So, people should keep themselves away from such fraud conspiracy. Sometimes misleading statements are made that research is 'currently underway' and internet and social media managers are trying to misuse these statements for fraudulent claims. Manufacturers, marketers and media together may be working in the dietary supplement fraud business for economic gains. People should be aware and identify such fraud agencies and protect themselves from socio-economic and health loss. Non-science based testimonials are supporting the products often from celebrities as a part of marketing. The promotion of such dietary supplement claims includes regulatory loopholes that prevent the producers from labelling and selling the products under dietary supplements. Experts and nutritionists from non-accredited organizations, research scientists who go to public with their findings before their research approved, all are the part of fraud system that people should be aware of and believe and keep consuming healthy and sustainable diet with enough physical exercise as guided by WHO. Receive a referral from personal doctors or local hospitals and authentic Academy of nutrition. Search on credible websites ending in edu., gov. or org. and always cross check information from websites ending in in, com or net or any print or electronic media.

\section{CONCLUSION}

Dietary supplements continue to increase in popularity among consumers who seek natural alternatives to prescription drugs. The consequences of the intake of dietary supplements goes on increasing with the increase in consumption. Dietary supplements are a unique category of consumer products with unique challenges. However, the regulatory loopholes allow fraudsters to sell them merely for economic gains. The scope of dietary supplement fraud is global bringing a risk to public health. Effective measures to combat DSF require understanding of the business model.

DSF differs from both food and prescription drug fraud. Fraudsters intentionally add active ingredients to dietary supplements in order to increase effectiveness and customer satisfaction but do not display the contents on the labels to avoid regulatory complications. Unfortunately, the consumers are not aware of this fraud and its harmful consequences to public health.

After Dietary Supplement Health and Education removed regulatory preapproval requirements, dietary supplements flooded the market and the fraudsters took this opportunity for economic gains, at the cost of public health. So, developing understanding of DSF and related criminology can certainly protect the targeted population from the socio-economic and health loss.

\section{REFERENCES}

[1] Is It Really 'FDA Approved?'. (2017). Retrieved from https://www.fda.gov/consumers/consumer-updates/it-really-fda-approved

[2] Food Labelling: Revision of the Nutrition and Supplement Facts Labels: Guidance for Industry Small Entity Compliance Guide. (2020). https://www.fda.gov/media/134505/download

[3] Nutrition and functional foods. (2020). https://www.assocham.org/userfiles/Knowledge\%20Report\%20$\% 20$ Nutrition $\% 20$ and $\% 20$ Functional $\% 20$ Foods.pdf 
[4] Dwyer, J., Coates, P., \& Smith, M. (2018). Dietary Supplements: Regulatory Challenges and Research Resources. Nutrients, 10(1), 41. https://doi.org/10.3390/nu10010041

[5] Economically motivated adulteration: implications for food protection and alternate approaches to detection. (2013).

https://conservancy.umn.edu/bitstream/handle/11299/153189/Everstine_umn_0130E_13646.p df? sequence $=1$ \&isAllowed $=y$

[6] Food Fraud and "Economically Motivated Adulteration" of Food and Food Ingredients. (2014, January). http://www.fredsakademiet.dk/ORDBOG/lord/food_fraud.pdf

[7] Going Beyond FDA's Food Protection Plan: Modernizing U.S. Food Safety Law. (2007). https://www.cspinet.org/sites/default/files/attachment/csdhelp.pdf

[8] Federal Trade Commission. Federal Trade Commission. (2020). Retrieved 17 October 2020, from https://www.ftc.gov/.

[9] FSSAI. Fssai.gov.in. (2020). Retrieved 20 October 2020, from https://fssai.gov.in/cms/healthsupplements.php.

[10] Federal judge enters consent decree against Tennessee drug, dietary supplement and device distributors, Basic Reset and Biogenyx, for drug, device and dietary supplement violations. U.S. Food and Drug Administration. (2020). Retrieved 20 October 2020, from https://www.fda.gov/news-events/press-announcements/federal-judge-enters-consent-decreeagainst-tennessee-drug-dietary-supplement-and-device.

[11] Tainted Products Marketed as Dietary Supplements_CDER. Accessdata.fda.gov. (2020). Retrieved 20 October 2020, from https://www.accessdata.fda.gov/scripts/sda/sdNavigation.cfm?sd=tainted_supplements_cder.

[12] Office of Dietary Supplements - Consumer Protection. Ods.od.nih.gov. (2020). Retrieved 21 October 2020, from https://ods.od.nih.gov/HealthInformation/consumerprotection.sec.aspx.

[13] Nccih.nih.gov. (2020). Retrieved 21 October 2020, from https://www.nccih.nih.gov/.

[14] Myszkowska-Ryciak, J., \& Harton, A. (2019). Eating Healthy, Growing Healthy: Outcome Evaluation of the Nutrition Education Program Optimizing the Nutritional Value of Preschool Menus, Poland. Nutrients, 11(10), 2438. https://doi.org/10.3390/nu11102438

[15] Global Food Fraud Trends and Their Mitigation Strategies: The Case of Some Dairy Products: A Review. (2020). [Ebook]. Retrieved 21 October 2020, from.

[16] Wiley. (2016). Adulteration of Dietary Supplements by the Illegal Addition of Synthetic Drugs: a review [Ebook]. Retrieved 21 October 2020, from.

[17] Springer. (2020). Food Fraud Prevention [Ebook]. Retrieved 21 October 2020, from https://core.ac.uk/display/326762605? source $=3$.

[18] Woodside, J. (2005). Micronutrients: dietary intake vs. supplement use [Ebook]. Retrieved 3 October 2020, from https://core.ac.uk/reader/192573674.

[19] Gardiner, P. (2006). Factors Associated With Dietary Supplement Use Among Prescription Medication Users [Ebook]. Retrieved 15 September 2020, from https://core.ac.uk/reader/213120406.

[20] United States Government Printing Office Washington. (2011). Agricultural Statistics 2011. Washington. 